\title{
Pembelajaran Inkuiri Terbimbing Berbantuan Alat Peraga Konstanta Pegas Digital untuk Meningkatkan Keterampilan Generik Sains
}

\author{
N. Khoiri* , C. Huda, dan H. Assegaff \\ Prodi Pendidikan Fisika, FPMIPATI, Universitas PGRI Semarang, Indonesia \\ *Email: nurkhoiri78@gmail.com
}

Received: July 18th, 2020. Accepted: August 19th, 2020. Published: August 31st 2020

\begin{abstract}
Abstrak
Telah dilakukan penelitian untuk menguji efektivitas pembelajaran inkuiri terbimbing dengan bantuan alat peraga konstanta pegas digital dalam meningkatkan keterampilan generik sains siswa. Penelitian ini dilaksanakan di SMAN 11 Semarang dengan subjek penelitian adalah siswa kelas XI MIPA dengan jumlah sampel 70 orang, terdiri atas 35 siswa kelas eksperimen dan 35 siswa kelas kontrol. Desain penelitian ini menggunakan Quasy Experiment Design. Tipe desain penelitian yang digunakan yaitu Nonequivalent Control Group Design. Teknik pengumpulan data dilakukan melalui observasi dan angket dengan skala Likert. Hasil analisis data pada instrumen observasi menunjukkan rata-rata nilai keterampilan generik sains kelas eksperimen $=3,22$ dan kelas kontrol $=2,93$. Hasil uji independent sample $t$-test menunjukkan bahwa $t_{\text {hitung }}>t_{\text {tabel }}$ yaitu $3,76>1,99$. Berdasarkan hasil tersebut diartikan $t_{\text {hitung }}>t_{\text {tabel }}$ maka Ho ditolak dan Ha diterima. Hasil penelitian ini menunjukkan bahwa pembelajaran inkuiri terbimbing berbantuan alat peraga kostanta pegas digital memberikan pengaruh positif terhadap keterampilan generik sains siswa. Keterampilan generik sains siswa lebih baik setelah penerapan pembelajaran inkuiri terbimbing berbantuan alat peraga.
\end{abstract}

\begin{abstract}
The research purpose is explored the effect of guided inquiry learning with digital spring for science generics skills. The subject of research are 70 student in XI MIPA SMAN 11
\end{abstract}


Semarang consisting of 35 students in the experimental group and 35 students in the control group. Design study uses Quasy Experiment Design, the type to be used is Nonequivalent Control Group Design. Data collection techniques through observation and questionnaire with a Likert scale. The results of data analysis from observation sheet on average experiment class $=3,22$ and the average control class $=2,93$. This study uses independent sample $t$-test show $t_{\text {count }}>t_{\text {table }}$ that is $3,76>1,99$ interpreted $t_{\text {count }}>t_{\text {table }}$ then Ho rejected Ho and accepted Ha. Based on the result of this research, it can be concluded that guided inquiry learning digital spring constant give positive influence to science generic skill student in SMAN 11 Semarang. Students' generic science skills were better after the implementation of guided inquiry learning assisted with teaching aids. (02020PERJ

Keywords: Guided inquiry learning; science generic skills; spring constant.

\section{PENDAHULUAN}

Fisika merupakan salah satu cabang ilmu pendidikan sains yang menghadapi tantangan global dan berkembang pesat pada abad ke 21. Salah satu strategi menghadapi tantangan ini adalah dengan meningkatkan mutu pendidikan melalui perbaikan kualitas pengajaran. Perbaikan dalam pembelajaran dengan cara mengubah sistem pembelajaran berpusat pada guru (teacher centered) menjadi pembelajaran berpusat pada siswa (student centered). Pada kenyataanya, pembelajaran di lapangan khususnya sekolah menengah masih marak penggunaan metode konvensional berpusat pada guru (teacher centered). Guru menerapkan masih menggunakan metode konvensional dengan banyak ceramah untuk mempersingkat waktu, mentuntaskan materi, dan memudahkan penilaian. Metode ceramah dan diskusi yang sudah familiar diterapkan didominasi oleh peran guru dengan alokasi waktu yang cukup.

Pembelajaran yang didapatkan siswa hendaknya memberikan pembekalan pemahaman konsep dan prosedur ilmiah untuk mengembangkan kecakapan berpikir, pengetahuan diri dan pemahaman tentang topik-topik khusus tertentu dalam wujud penerapan pembelajaran inkuiri. Model pelaksanaan pembelajaran yang dirancang dan didesain untuk memberi siswa pengalaman prosedur ilmiah yang diwujudkan dalam pembelajaran inkuiri. Prosedur ilmiah dapat berupa 
sebuah pola pemikiran yang menekankan pada pengusulan pertanyaan, merumuskan dan mengembangkan hipotesis agar dapat menjawab pertanyaanpertanyaan dan menguji hipotesis dengan data ilmiah (Eggen \& Kauchak, 2012). Proses inkuiri yang terjadi berupa kegiatan mengajukan permasalahan, mengusulkan prediksi, dan menguji melalui data sebenarnya sehingga siswa mendapatkan pengalaman baru atau modifikasi agar mampu memecahkan permasalahan melalui suatu penyelidikan.

Inkuiri didefinisikan sebagai pembelajaran yang mengajak siswa terlibat melalui kegiatan bertahap dalam mencapai target menemukan makna. Siswa terlibat dalam berinkuiri melalui tahap pengusulan pertanyaan, pengumpulan data informasi dan melaksanakan investigasi (Azizah et al., 2019). Inkuiri merupakan pendekatan pembelajaran yang dapat di terapkan pada semua jenjang pendidikan. Pembelajaran inkuiri berorientasi kecakapan siswa dan pemecahan masalah berdasarkan investigasi. Guru dapat memberikan bantuan dalam mengembangkan keterampilan dan sikap dalam pemecahan masalah siswa. Hal ini penting dalam membelajarkan siswa untuk menemukan masalah dengan mandiri (Baharuddin, 2017).

Inkuiri terbimbing merupakan model pembelajaran yang berpusat pada siswa (Bilgin, 2009). Peran guru dalam penerapan model pembelajaran inkuiri terbimbing berbeda dengan peran guru saat menggunakan pembelajaran konvesional (Olibie \& Ezeoba, 2014). Guru bukan berperan sebagai fasilitas yang memberikan data informasi dan siswa sebagai penerima informasi, tetapi guru berperan untuk membuat rencana pembelajaran; sedangkan siswa secara aktif berperan dalam mengembangkan pembelajaran (Zion \& Mendelovici, 2012). Konstruksi informasi dan data dapat ditumbuhkan melalui kegiatan dan kecakapan siswa berpikir yang sangat dibutuhkan dalam konstruksi informasi dan menambah pengalaman (Susilawati et al., 2015).

Model inkuiri bertujuan dalam rangka mencapai kecakapan berpikir tingkat tinggi, sehingga siswa memeroleh kecakapan dalam keterampilan pemecahan masalah. Pembelajaran inkuiri merangsang keaktifan siswa sebagai subjek yang belajar. Siswa harus bertanggung jawab dengan berperan aktif dalam pembelajaran. Keunggulan pembelajaran inkuiri tergambar dari proses pembimbingan mengkonstruksi informasi data dalam pemecahan masalah (Khalid \& Azeem, 2012). Selanjutnya di akhir pembelajaran muncul harapan kepada siswa agar dapat meningkatkan kegiatan ilmiah dan penalaran yang didukung dengan konsepsi ilmiah (Smyrnaiou, Moustaki \& Chronis, 2012). 
Berdasarkan uraian tersebut, pembelajaran inkuiri dideskripsikan menjadi suatu pembelajaran yang menjadikan siswa siap dalam investigasi. Pembelajaran ini mengajak siswa menemukan pengetahuan baru. Cara pandang inkuiri ini membantu pengembangan pola dan cara berpikir kritis secara ilmiah dengan bantuan guru sebagai fasilitator. Jika kecakapan berpikir mampu dikuasai siswa maka siswa menjadi aktif dan kreatif. Cara pandang inkuiri yang memicu kreativitas merupakan bagian dari cara pandang dalam belajar fisika.

Pembelajaran sains yang memfasilitasi keterampilan generik sains dapat dikelompokkan menjadi sembilan indikator, yaitu: pengamatan secara langsung (direct observation), pengamatan secara tidak langsung (indirect observation), kesadaran mengenai skala besaran (sense of scale), bahasa dalam simbolik (symbolic languange), kerangka dalam logika (logical selfconsistency) dari hukum alam, inferensi dalam logika (logical inference), hukum sebab akibat (causality), model matematika (mathematical modeling), dan membangun konsep ilmiah (concept formation). Kecakapan berpikir khusus secara generik akan tumbuh melalui pembelajaran fisika secara aktif dan kreatif (Brotosiswoyo, 2001; Khoiri, et al., 2018).

Fisika dianggap sebagai mata pelajaran yang sulit bagi siswa SMA. Kesulitaan yang dialami siswa muncul karena pemahaman konsep fisika yang kurang dan siswa tidak suka dengan mata pelajaran fisika (Samudra, 2014). Selain itu, pembelajaran fisika yang kurang kontekstual dan dominasi peran guru di kelas dengan direct instruction juga membuat siswa tidak mampu memahami konsep dengan baik (Rais, et al., 2020).

Berdasarkan pengalaman pada magang satu, magang dua, dan magang tiga di sekolah, guru masih menggunakan metode pembelajaran konvensional. Metode konvensional membuat siswa bosan karena pembelajaran yang terkesan monoton. Oleh karena itu, guru harus kreatif dalam menggunakan media pembelajaran yang ada. Pembelajaran fisika banyak mengandung konsep-konsep yang susah dimengerti apabila hanya diajarkan secara teoritis; untuk itu dibutuhkan alat peraga untuk menggambarkan konsep-konsep tersebut.

Kegiatan praktikum sangat mendukung penguasaan dan pemahaman teori. Kegiatan praktikum diimplementasikan dalam pembelajaran inkuiri yang mengarah pada minimal penguasaan dan pemahaman konsep serta keterampilan generik sains. Siswa tidak hanya dilatih menyusun, menggunakan, serta mamanipulasi alat; tetapi juga mengembangkan keterampilan dasar, khususnya pada keterampilan generik sains. Keterampilan inilah yang akan 
bermanfaat bagi siswa untuk bekal penguatan materi di level yang lebih tinggi, ketika menghadapi permasalahan yang harus dipecahkan secara tepat, cepat, dan sistematis.

Pandangan siswa terhadap pelajaran fisika harus diubah; tidak lagi pelajaran yang sulit tetapi menjadi pelajaran yang menyenangkan. Pembelajaran inkuiri terbimbing disertai dengan kegiatan praktikum akan membuat siswa lebih antusias dalam melakukan berbagai macam percobaan, sehingga dapat memunculkan berbagai keterampilan sains masing masing siswa. Kegiatan praktikum membuat siswa merasa tertantang untuk membuktikan berbagai teori fisika. Siswa tidak lagi beranggapan bahwa fisika itu sulit dan membosankan, namun berubah menjadi pelajaran yang menyenangkan. Melalui pembelajaran inkuiri tersebut, secara tidak langsung kemampuan generik sains siswa akan meningkat dengan sendirinya. Hal ini juga akan berdampak pada hasil belajar siswa yang menjadi lebih baik.

Berdasarkan latar belakang dan permasalahan yang telah dipaparkan, penelitian ini penting dilakukan untuk menguji efektivitas pembelajaran inkuiri terbimbing melalui alat peraga konstanta pegas digital dalam meningkatkan keterampilan generik sains.

\section{METODE}

Penelitian ini menggunakan quasy experiment design. Tipe yang digunakan yaitu nonequivalent control group design. Populasi dalam penelitian ini yaitu siswa kelas XI MIPA SMAN 11 Semarang. Penelitian ini dilakukan menggunakan dua sampel kelas, yaitu kelas XI MIPA 4 sebagai kelas kontrol dan kelas XI MIPA 5 sebagai kelas eksperimen melalui teknik cluster random sampling. Kelas ekperimen diberi pembelajaran inkuiri dengan praktikum berbantuan alat peraga konstanta pegas digital; sedangkan kelas kontrol tidak menggunakan alat peraga konstanta pegas digital. Sampel yang digunakan dalam penelitian ini berjumlah 70 siswa yang terdiri atas 35 siswa kelas eksperimen dan 35 siswa kelas kontrol. Instrumen yang digunakan dalam penelitian ini adalah lembar observasi dan angket untuk mengetahui keterampilan generik sains.

Tahapan penelitian terdiri atas tahap rencana persiapan, pelaksanaan, serta analisis akhir dan penarikan kesimpulan. Tahap persiapan meliputi studi awal, kajian literatur, menentukan sampel dari jumlah populasi, menyusun instrumen penelitian. Tahap pelaksanaan 
dilakukan di SMAN 11 Semarang dengan menerapkan pembelajaran inkuiri terbimbing berbantuan alat peraga konstanta pegas digital. Observasi terhadap keterampilan generik sains dilakukan ketika pembelajaran berlangsung, dan pemberian kuisioner kepada siswa dilakukan di akhir pembelajaran. Pada tahap akhir, dilakukan pengolahan dan analisis data yaitu menguji homogenitas data, mendeskripsikan data dengan mentabulasi data hasil penelitian, serta menguji statistik menggunakan independent sample $t$ test dan penarikan kesimpulan.

\section{HASIL DAN PEMBAHASAN}

Penelitian ini telah dilakukan dengan tahapan-tahapan inkuiri untuk menghasilkan data yang akurat melalui instrumen observasi dan angket. Lembar observasi keterampilan generik sains siswa berisi 12 indikator penilaian dari sembilan aspek yang diukur, meliputi: pengamatan secara tak langsung, pengamatan secara langsung, kesadaran akan skala, bahasa dengan simbolik, pemodelan matematika, kerangka dalam logika, hukum sebab dan akibat, konsistensi logis dan membangun konsep ilmiah. Hasil analisis data obsevasi penelitian diperoleh seperti Tabel 1.

Efektivitas pembelajaran inkuiri terbimbing berbantuan alat peraga konstanta pegas digital dapat diketahui dengan pengujian hipotesis yang diperoleh melalui uji independent sample t-test. Uji statistik ini untuk mengetahui perbedaan keterampilan generik sains siswa antara kelas eksperimen dan kelas kontrol. Keterampilan generik sains dapat diketahui dari perbedaan nilai observasi kelompok eksperimen dan kelompok kontrol. Hasil $t_{\text {hitung }}>$ $t_{\text {tabel, }}$ menunjukkan bahwa pembelajaran inkuiri terbimbing berbantuan alat peraga mampu meningkatkan keterampilan generik sains siswa.

Tabel 1. Hasil analisis data observasi keterampilan generik sains.

\begin{tabular}{lccl}
\hline Kelas & $\begin{array}{c}\text { Rata- } \\
\text { rata }\end{array}$ & $\begin{array}{c}\text { Kondisi } \\
\text { Awal }\end{array}$ & Uji t \\
\hline Eksperimen & 3,22 & Homogen & $t_{\text {hitung }}$ \\
Kontrol & 2,93 & & 3,76 \\
\hline
\end{tabular}

Pengajaran dengan pendekatan inkuiri membuat siswa tertarik untuk menemukan hipotesis hasil percobaan (Manzoor, 2009). Pembelajaran inkuiri terbimbing mendorong siswa untuk belajar melalui keterlibatan aktif dan mengadakan suatu penelitian (percobaan) untuk menemukan suatu konsep. Pembelajaran inkuiri memacu siswa untuk memecahkan masalah secara mandiri dan memiliki keterampilan generik sains dalam menganalisis informasi.

Alat peraga konstanta pegas digital adalah alat yang digunakan untuk mendeteksi pertambahan panjang dari suatu massa benda dan mengetahui nilai konstanta 
pegasnya. Alat pendukung konstanta pegas digital adalah sensor ultrasonik HC-SR04 yang secara otomatis menampilkan panjang pegas pada LCD. Selain itu, alat peraga ini dapat menvariasi massa benda dan pegas yang dikemas dalam kegiatan praktikum menggunakan alat konstanta pegas digital untuk membuktikan teori Hukum Hooke yang menyatakan bahwa pertambahan panjang berbanding lurus dengan gaya yang diberikan pada benda.

Pada penilaian observasi siswa, hasil analisis indikator keterampilan generik sains siswa kelas eksperimen lebih baik dibandingkan dengan kelas kontrol. Jumlah skor nilai dari masingmasing indikator keterampilan generik sains dapat dilihat pada Tabel 2.

Tabel 2. Hasil observasi ketrampilan generik sains siswa kelas kontrol dan kelas eksperimen.

\begin{tabular}{clcc}
\hline \multirow{2}{*}{ No } & \multicolumn{1}{c}{ Indikator KGS } & \multicolumn{2}{c}{ Nilai Keterampilan Generik Sains } \\
\cline { 3 - 4 } & & Kelas Kontrol & Kelas Eksperimen \\
\hline 1 & Pengamatan secara tak langsung & 3,53 & 3,56 \\
2 & Pengamatan secara langsung & 3,29 & 3,43 \\
3 & Kesadaran akan skala & 3,71 & 3,80 \\
4 & Bahasa dengan simbolik & 3,94 & 3,86 \\
5 & Pemodelan matematika & 3,54 & 3,14 \\
6 & Kerangka dalam logika & 1,91 & 2,74 \\
7 & Hukum sebab akibat & 1,86 & 2,63 \\
8 & Konsistensi logis & 2,51 & 2,98 \\
9 & Membangun konsep & 2,31 & 2,97 \\
\hline
\end{tabular}

Hasil observasi menunjukkan nilai keterampilan generik sains tiap indikator berada pada kategori tinggi dan sedang. Keterampilan generik sains siswa pada indikator hukum sebab akibat tergolong kategori rendah. Rendahnya indikator hukum sebab akibat memunculkan dugaan bahwa kemampuan siswa menganalisis suatu masalah masih kurang. Kemampuan menganalisis sendiri merupakan aktivitas berpikir tingkat tinggi yang sesuai dalam pembelajaran inkuiri terbimbing. Hal ini sejalan dengan hasil penelitian bahwa indikator hukum sebab akibat mengalami peningkatan yang lebih rendah karena memerlukan kemampuan berpikir tingkat tinggi (Sunyono, 2010). Penelitian serupa menyatakan indikator hukum sebab akibat mengalami peningkatan terendah (Gunawan, Setiawan, \& Widyantoro, 2013). Keberhasilan 
pembelajaran inkuiri terbimbing berbantuan alat peaga konstanta pegas digital untuk meningkatkan keterampilan generik sains dalam kategori tinggi memerlukan waktu yang lama sampai siswa dapat menyelesaikan berbagai jenis masalah lainnya. Hasil penelitian Selvianti, Ramdani \& Jusniar (2013) menyatakan bahwa untuk melatih keterampilan generik sains diperlukan waktu yang lebih lama terutama untuk indikator hukum sebab akibat.

Respons siswa terhadap pembelajaran inkuiri berbantuan alat peraga konstanta pegas digital diketahui melalui penilaian pada setiap aspek melalui lembar angket. Hasil angket respons siswa kelas eksperimen dari setiap aspek disajikan pada Tabel 3.

Tabel 3. Angket respons siswa kelas eksperimen terhadap panduan dan alat peraga konstanta pegas digital.

\begin{tabular}{clcc}
\hline No & \multicolumn{1}{c}{ Aspek } & Nilai & Kategori \\
\hline 1 & Kemudahan & 3,55 & Sangat Baik \\
2 & Kebermanfaatan & 3,39 & Sangat Baik \\
3 & Kemenarikan & 3,33 & Sangat Baik \\
4 & Keamanan & 3,52 & Sangat Baik \\
5 & Waktu & 3,54 & Sangat Baik \\
\hline
\end{tabular}

Hasil respons siswa terhadap pembelajaran inkuiri berbantuan alat peraga konstanta pegas digital pada aspek kemenarikan memeroleh nilai terendah dari lima aspek penilaian. Tampilan alat peraga yang masih sederhana dapat didesain lebih menarik untuk meningkatkan respons siswa terhadap alat yang digunakan. Penerapan pembelajaran inkuiri berbantuan alat peraga konstanta pegas digital dapat meningkatkan keterampilan generik sains siswa. Peningkatan tersebut terlihat pada hasil obsevasi keterampilan generik sains siswa lebih tinggi pada kelas eksperimen. Keterampilan generik sains terkait pengalaman belajar siswa dilakukan dengan penerapan pembelajaran inkuiri (Samudra, 2014). Keterampilan generik sains pada tiap aspek sedikit berkembang karena pembelajaran lebih dominan secara praktikum yang cukup menambah pengalaman (Yuniarita, 2014; Ermawati, Sugiarto \& Vebrianto, 2018). Pengalaman belajar menggunakan alat peraga yang mudah, menarik dan praktis dalam pembelajaran inkuiri dapat membantu siswa untuk memiliki keterampilan tertentu.

\section{KESIMPULAN}

Keterampilan generik sains siswa yang menggunakan pembelajaran inkuiri terbimbing berbantuan alat peraga konstanta pegas digital lebih tinggi secara signifikan 
dibandingkan dengan siswa yang pembelajarannya tidak berbantuan alat peraga konstanta pegas digital. Hal tersebut menjelaskan bahwa pembelajaran inkuiri terbimbing berbantuan alat peraga kostanta pegas digital memberikan pengaruh positif terhadap keterampilan generik sains siswa. Keterampilan generik sains tiap indikator berada pada kategori tinggi dan sedang. Respons siswa terhadap pembelajaran inkuiri berbantuan alat peraga konstanta pegas digital berada pada kategori sangat baik.

\section{DAFTAR PUSTAKA}

Azizah, L. M., Poernomo, J. B., \& Faqih, M. I. 2019. Pengembangan Modul Pembelajaran Fisika Kekas XI MA/SMA Berbasis Guided Inquiry pada Materi Alat-Alat Optik. Physics Education Research Journal, 1(1): 11-20. https:// doi.org/10.21580/perj .2019.1.1.4006

Baharuddin, 2017. Perangkat Pembelajaran IPA Berbasis Inkuiri Terbimbing Dengan Tugas Proyek Materi Sistem Ekskresi Untuk menuntaskan Hasil Belajar Siswa SMP. Jurnal IPA dan Pembelajaran IPA. 1(1): 81-89.

Bilgin, I. 2009. The Effect Of Guided Inquiry Instruction Incorporating A Cooperative Learning Approach On University Students Achievement of Acid and Base
Concepts and Attitude Toward Guided Inquiry Instuction. Scientific Research And Essay, 4(3): 1038-1046.

Brotosiswoyo, B. 2001. Hakikat Pembelajaran MIPA di Perguruan Tinggi. Jakarta: PAU-PPAI-UT. Eggen, P. \& Kauchak, D. 2012. Strategi dan Model Pembelajaran Edisi Keenam. Jakarta: PT. Indeks.

Ermawati, E., Sugiarto, R. \& Vebrianto, R. 2018. Penerapan Pembelajaran Inkuiri Terbombing untuk Meningkatkan Keterampilan Generik Sains Siswa. Jurnal of Natural Science Integration, 1 (2): 213-220

Gunawan, Setiawan, A., \& Widyantoro, D.H. 2013. Model Virtual Laboratory Fisika Modern Untuk Meningkatkan Keterampilan Generik Sains Calon Guru. Jurnal Pendidikan dan Pembelajaran, XX(1): 25-32.

Khalid, A. 2012. Constructivist Vs Traditional: Effective Instructional Approach in Teacher Education. International Journal of Humanities and Social Science, 2(5): 170-177.

Khoiri, N., Rusilowati, A., W.\& S., $2018 . \quad$ Mengajarkan Pemahaman Konsep Gerak Parabola Berbantuan Alat Peraga. Jurnal Penelitian Pembelajaran Fisika. Jurnal Penelitian Pembelajaran Fisika, 9(2): 119-124. 
Manzoor, A. K. 2009. Teaching of heat and temperature by hypothecal inquiry approach: A sample on inquiry teaching. Journal of Pysics Teacher Education Online, 5(2): 43-46.

Olibie, E. I. \& Ezeoba, K. O. 2014. Ability and Location Differences in the Effect of Guided Inquiry on Nigerian Student's Achievement in Social Studies Curriculum. Jurnal of Education and Human Development, 3(4): 335-344.

Rais, A. A., Hakimm, L. \& Sulistiawati. 2020. Pemahaman Konsep Siswa melalui Model Inkuiri Terbimbing Berbantuan Simulasi PhET. Physics Education Research Journal, 2(1): 1-8.

Samudra, G.B. 2014. PermasalahanPermasalahan yang Dihadapi Siswa SMA di Kota Singaraja dalam Mempelajari Fisika. Jurnal Pendidikan dan Pembelajaran IPA Indonesia, 4(1): 1-7.

Selvianti, Ramdani, \& Jusniar. 2013. Evektivitas Metode Pemecahan Masalah untuk Meningkatkan Hasil Belajar dan Keterampilan Generik Sains Siswa Kelas XI IPA 2 SMAN 8 Makasar (Studi Pada Materi Pokok Hidrolisis Garam). Jurnal Chemica, XIV(1): 55-65.
Smyrnaiou, Z., Moustaki. F. \& Chronis, K. 2012. Student's Constructionist Game Modelling Activities as Part of Inquiry Learning Process. Journal of e-Learning, 10(2): 235248.

Sunyono. 2010. Pengembangan Model Lembar Kerja Siswa Berorientasi Keterampilan Generik Sains pada Materi Kesetimbangan Kimia. Prosiding Seminar Nasional Kimia dan Pendidikan Kimia, II: 464-469.

Susilawati, Ristanto, S. \& Khoiri, N. 2015. Real Laboratory Learning and Self Assignment of Physics on Vocational as 21st Centuury Skills. Jurnal Pendidikan Fisika Indonesia, 11(1): 73-83.

Yuniarita, F. 2014. Penerapan Pembelajaran Inkuiri Terbimbing untuk Meningkatkan Keterampilan Generik Sains Siswa SMP. Jurnal Pengajaran MIPA, 19(1): 111-116

Zion, M. \& Mendelovici, R.M. 2012. Moving from Structured to Open Inquiry: Challenges and Limits. Science Education International, 23(4): 383-399. 